\title{
Economic Valuation of Ecosystem Services by Using the Analytic Hierarchy Process and the Analytic Network Process. Comparative Analysis Between Both Methods in the Albufera Natural Park of València (Spain)
}

\author{
David Jorge-García*, Vicente Estruch-Guitart \\ Dept. of Economics and Social Sciences, Polytechnic University of Valencia, València 46022, Spain
}

Corresponding Author Email: dajorga2@etsiamn.upv.es

https://doi.org/10.18280/ijdne.150101

Received: 8 February 2019

Accepted: 19 February 2019

\section{Keywords:}

environment, RAMSAR, environment policy, economic valuation, agriculture, AMUVAM, Sustainability, SDG

\begin{abstract}
The Analytic Multicriteria Valuation Method (AMUVAM) was designed to value environmental assets. This method and its software allow one to incorporate all the experts' decisions in a global evaluation matrix and assign a degree of importance (weight) to the criteria. This multicriteria decision aid methodology has traditionally been based on the Analytic Hierarchy Process (AHP) and the Discounted Cash Flow. However, it can be substituted by the Analytic Network Process (ANP). Although it involves a higher complexity, it considers all the current relationships between the different alternatives and criteria so it should be more accurate. Therefore, the aim of the present work is to value the ecosystem services of an environmental area by using both methods and compare the results. A real application has been presented; therefore, this work has been applied to the valuation of the Albufera Natural Park in València (Spain). This area is considered one of the most important Mediterranean wetlands of the Mediterranean countries. Having obtained the results, the method can be carried out using either of the two processes when the aim of the assessment is to get the Total Economic Value. In this case, the AHP can be used as a less time-consuming and cheaper method. However, if the goal is to value the ecosystem services, there are significant differences between both methods. Some of the services are overvalued or underestimated when the AHP has been used.
\end{abstract}

\section{INTRODUCTION}

Many natural areas generate endless externalities, which have an impact on society. "It happens when discussing about the environment protection, landscape production or air quality improvement in cities, regions or even countries near those areas" [1, 2]. Furthermore, "society continues to inadequately value all the environmental sources which are not being part of the market" [3, 4]. Aznar and Estruch [5] report that these wrong considerations cause market failures, which provoke that "people do not figure out the real value of the goods and services which are produced by the different ecosystems". The valuation of natural spaces is, therefore, "a key mechanism to study the acceptance of the ecosystems management by society" [6].

The study of ecosystem services has been increasing in the recent years and today, its interest is one of the centers of the global initiative. As a result, many researchers, universities and even national and international organizations are publishing multiple information related to this field. Hamel and Bryant [7] report that despite having this kind of research a theoretical focus in origin, they are usually related to a future objective based on environmental policy. Therefore, the valuation can be essential to study their impacts and their current situation to have enough information for a future decision-making in the area.

There are different ways of valuating but the multicriteria methods are the suitable ones when it comes to environment areas. The Analytic Multicriteria Valuation Method is traditionally based on the Analytic Hierarchy Process (AHP) and the Discounted Cash Flow. Despite being a proper combination in many cases, the AHP can be substituted by a more complex method called Analytic Network Process. This one considers all the relationships between the different criteria so it is more precise. The aim of this work is to compare the results obtained by both methods AHP and ANP on the studied area, the Albufera Natural Park of Valencia (Spain).

\section{CONTEXTUALIZATION AND METHODOLOGY}

\subsection{The Albufera Natural Park}

The Albufera Natural Park of Valencia (the third biggest city in Spain) is placed in the Mediterranean coast line about 7.5 kilometers south of the Turia river mouth. Nowadays, the Natural Park has an approximate surface area of $211.2 \mathrm{~km}^{2}$, although the freshwater lagoon is about $23.94 \mathrm{~km}^{2}$. Most of the surface is taken up by fields with rice crops and marshlands.

This area was declared as a Natural Park in 1986 and afterwards it was included among the 'International Important Wetlands record' established by the Ramsar agreement [7].

This Natural Park is one of the most significant wetlands in Europe and a population of up to one million inhabitants surrounds it. Despite its ecological and economic value, there have been several negative environmental impacts related to the water quality or the biodiversity loss since the $80 \mathrm{~s}$, which 
have been produced by the ongoing lake's eutrophication or the progressive devaluation of the forest area.

Apart from the crops, other economic activities can be found in this area such as hunting and fishing, even though both have been reduced during the last decades. In addition, some spaces of the Albufera Natural Park are receiving many tourists due to the aesthetic, landscape and recreational value of the area.

Finally, it is necessary to consider the cultural services such as paintings, literature or religious festivals. For instance, painters such as Joaquín Sorolla or writers such as Vicente Blasco Ibáñez have been inspired by this place as many people are due to the identity value of the area. Moreover, the Latin sailing and the traditional fishing which have been both declared as a Good of Cultural Interest by the Valencian Regional Government in 2018.

\subsection{Ecosystem services}

The concept of the ecosystem services has been the result from an intense debate during many years. Although there are many different definitions, they can be defined as "those aspects of the ecosystem used directly or indirectly to generate human well-being" [8]. Constanza et al. [3] were the first scientists who started the first classification. In spite of the fact that other researchers have created other lists since that moment, none of them always fit everywhere [9]. In this work, the Millennium Ecosystem Assessment list has been chosen owing to its international recognition. This Assessment was created by the NUO and it was agreed by scientists from more than 95 countries, being the most used one by the international organizations and public administrations [10].

Table 1. Ecosystem services considered in the study

\begin{tabular}{|c|c|}
\hline \multirow{4}{*}{ Cultural services } & Cultural value \\
\cline { 2 - 2 } & Tourism and recreation \\
\cline { 2 - 2 } & Aesthetics and inspiration \\
\cline { 2 - 2 } & Identity value \\
\cline { 2 - 2 } Supporting services & Social relationships \\
\cline { 2 - 2 } Provisioning services & Educational value \\
\hline \multirow{4}{*}{ Regulation services } & Putrient recycling \\
\cline { 2 - 2 } & Primary production \\
\cline { 2 - 2 } & Provision of genetic sources \\
\cline { 2 - 2 } & Fresh water supply \\
\cline { 2 - 2 } & Climate regulation \\
\hline \multirow{3}{*}{ and hunting) } \\
\cline { 2 - 2 } & Water sanitary \\
\hline
\end{tabular}

According to the Millennium Ecosystem Assessment, the ecosystem services are classified in four main groups: supporting services (those that are necessary for the production of all other ecosystem services), provisioning services (products obtained by the ecosystems), regulation services (benefits obtained from the regulation of ecosystem processes) and cultural services (nonmaterial benefits people obtain from ecosystems) [11]. The provisioning services are usually divided into two groups to separate the services that are part of the economic monetary market from the others. On the one hand, the market services include the three main economic activities, (considering only the provision services), which are agriculture, fishing and hunting. On the other hand, the second group includes the other provisioning services including the provisioning of fresh water and genetic materials. However, both subgroups of provisioning services are considered as a whole in this work.

In this work, the four groups of ecosystem services included in the Millennium Ecosystem Assessment have been valued. Each group have different ecosystem services depending on the characteristic of the ecosystem typology. Nevertheless, only the existent and relevant ones to the studied area have been considered (shown in Table 1), all of which chosen from the general list by considering the experts point of view.

\subsection{Methodology}

Both AHP and ANP allows us to calculate the importance or weight in percentages of each group of ecosystem services. In this case, all the ecosystem services have been valued individually when using ANP to consider all the relationship while only the four groups have been valued when using AHP. In order to compare the results resulted from each method; the ones obtained by ANP have been gathered in the four groups each service belong. The steps should be followed when valuating in AHP are explained by Saaty [12] while the ones related to ANP are explained by Saaty [13].

"The required judgments that are usually made in qualitative terms are expressed numerically. To do this, and not simply assigning a score out of a person's memory; reciprocal pairwise comparisons are made in a carefully designed scientific way" $[12,13]$. Therefore, the selected experts have prioritized the set of alternatives (ecosystem services) by using paired comparison matrices between their components following this method, all of which are listed below. The calculations have been done by using a selfsoftware.

- Dept. of Vegetal Production. Polytechnic University of Valencia.

- Dept. of Agroforestry Ecosystems. Polytechnic University of Valencia.

- $\quad$ SEO-Bird Life (ecologist NGO)

- 'Acció Ecologista Agró' (ecologist NGO)

- Fishermen Community 'El Palmar'.

- AVA-ASAJA Cooperative (farmer's union).

- 'La Unió' Cooperative (farmer's union).

- Appellation of Origin 'Arròs de València' Federation.

- Assut Foundation (public foundation)

- PAVAGUA (public company working on water sanity and environment)

All these people are professional biologists or engineers with technical and scientific knowledge in ecosystems so that the results are strong enough to be statically significant. They also show a broad vision of the social, ecological and economic reality of the area since the selected organizations encompass an important range of different points of view.

Judgments are given verbally as indicated in the scale of comparison established by Saaty $[12,13]$, which is shown in Table 2. "A corresponding number is associated with that judgment. The vector of priorities is the principal eigenvector of the matrix" $[12,13]$. The resulting eigenvectors of the last matrices are indicating the weight of each alternative or ecosystem service.

Associated with the weights and the matrices, there is always mathematically an inconsistency. In both cases, it has 
been obtained by calculating the consistency ratio (CR). "Overall, inconsistencies are accepted below 10\% for matrices of rank $n>4,5 \%$ for $n=3$ and $8 \%$ for $n=4$ " $[12,13]$.

Table 2. Scale of comparison $[12,13]$

\begin{tabular}{cc}
\hline $\begin{array}{c}\text { Intensity of } \\
\text { importance }\end{array}$ & Definition \\
\hline 1 & Equal importance \\
3 & Moderate importance \\
5 & Strong importance \\
7 & Very strong demonstrated importance \\
9 & Extreme importance \\
$2,4,6,8$ & Comparison between the above values \\
\hline
\end{tabular}

\section{RESULTS AND DISCUSSION}

After carrying out the ten interviews with the selected experts by using both methods, the weights or importance in percentage for the four groups of ecosystem services and for each expert have been obtained as shown in Table 3.

Table 3. Weights or importance (\%) obtained. (a) by using AHP; (b) by using ANP

\begin{tabular}{|c|c|c|c|c|}
\hline \multicolumn{5}{|c|}{ Analytic Hierarchy Process (AHP) } \\
\hline \multirow{3}{*}{ Expert } & \multicolumn{4}{|c|}{ Weights / Importance (\%) } \\
\cline { 2 - 5 } & SS & PS & RS & CS \\
& & & & \\
\hline AO & 21.62 & 62.72 & 4.91 & 10.75 \\
\hline DAE & 46.95 & 13.95 & 33.85 & 5.35 \\
\hline DVP & 11.41 & 43.27 & 23.66 & 23.66 \\
\hline PAV & 48.99 & 7.58 & 28.27 & 15.16 \\
\hline AF & 49.50 & 23.22 & 13.64 & 13.64 \\
\hline LU & 25.74 & 45.09 & 19.78 & 9.39 \\
\hline SEO & 44.09 & 7.45 & 40.38 & 8.08 \\
\hline FC & 33.83 & 16.92 & 28.79 & 20.46 \\
\hline AEA & 22.34 & 16.25 & 48.74 & 12.66 \\
\hline AVA & 12.50 & 62.50 & 12.50 & 12.50 \\
\hline
\end{tabular}

(a)

\begin{tabular}{|c|c|c|c|c|}
\hline \multicolumn{5}{|c|}{ Analytic Network Process (ANP) } \\
\hline \multirow{3}{*}{ Expert } & \multicolumn{4}{|c|}{ Weights / Importance (\%) } \\
\cline { 2 - 5 } & SS & PS & RS & CS \\
& & & & \\
\hline AO & 22.81 & 66.18 & 7.03 & 3.98 \\
\hline DAE & 43.19 & 12.11 & 44.39 & 0.31 \\
\hline DVP & 8.64 & 38.81 & 48.43 & 4.11 \\
\hline PAV & 52.71 & 8.95 & 37.82 & 0.52 \\
\hline AF & 56.64 & 22.29 & 19.84 & 1.22 \\
\hline LU & 29.69 & 35.21 & 33.47 & 1.63 \\
\hline SEO & 42.19 & 6.69 & 50.94 & 0.18 \\
\hline FC & 36.93 & 16.26 & 45.07 & 1.74 \\
\hline AEA & 20.83 & 14.10 & 64.32 & 0.75 \\
\hline AVA & 23.23 & 46.08 & 28.50 & 2.19 \\
\hline
\end{tabular}

(b)

Notes: On the one hand, the abbreviations of the experts are AO (Appellation of Origin), DAE (Dept. Agroforestry Ecosystems), DVP (Dept. Vegetal Production), PAV (PAVAGUA), AF (Assut Foundation), LU (La Unió), SEO (SEO-Bird Life, NGO), FC (Fishermen Community), AEA (Acció Ecologista Agró, NGO) and AVA (AVA-ASAJA). On the other hand, the abbreviations of the services are: SS (Supporting services), PS (Provisioning services), RS (Regulation services) and CS (Cultural Services).
As it can be seen, the existence of differences between the weights obtained by both methods is verified, even though the same experts have carried out both processes under the same conditions. However, another table has been done in order to analyze better the detected differences, which are shown in Table 4. This caption shows the difference between the weights obtained by AHP and the ones by ANP (AHP - ANP). On the one hand, the positive differences (AHP > ANP) are highlighted in blue whereas on the other hand, the negatives differences (AHP < ANP) are highlighted in red.

Table 4. Difference between both methods (\%)

\begin{tabular}{|c|c|c|c|c|}
\hline \multirow{2}{*}{ Expert } & \multicolumn{4}{|c|}{$\begin{array}{c}\text { Difference between the AHP and the ANP } \\
\text { results obtained (\%) }\end{array}$} \\
\cline { 2 - 5 } & & & & \\
& SS & PS & RS & CS \\
\hline AO & $-1.19 \%$ & $-3.46 \%$ & $-2.12 \%$ & $6.77 \%$ \\
\hline DAE & $3.76 \%$ & $1.84 \%$ & $-10.54 \%$ & $5.04 \%$ \\
\hline DVP & $2.77 \%$ & $4.46 \%$ & $-24.77 \%$ & $19.55 \%$ \\
\hline PAV & $-3.72 \%$ & $-1.37 \%$ & $-9.55 \%$ & $14.64 \%$ \\
\hline AF & $-7.14 \%$ & $0.93 \%$ & $-6.20 \%$ & $12.42 \%$ \\
\hline LU & $-3.95 \%$ & $9.88 \%$ & $-13.69 \%$ & $7.76 \%$ \\
\hline SEO & $1.90 \%$ & $0.76 \%$ & $-10.56 \%$ & $7.90 \%$ \\
\hline FC & $-3.10 \%$ & $0.66 \%$ & $-16.28 \%$ & $18.72 \%$ \\
\hline AEA & $1.51 \%$ & $2.15 \%$ & $-15.58 \%$ & $11.91 \%$ \\
\hline AVA & $-10.73 \%$ & $16.42 \%$ & $-16.00 \%$ & $10.31 \%$ \\
\hline \multicolumn{5}{|c|}{$\mathbf{A H P}>\mathbf{A N P}$} \\
\hline
\end{tabular}

Notes: On the one hand, the abbreviations of the experts are AO (Appellation of Origin), DAE (Dept. Agroforestry Ecosystems), DVP (Dept. Vegetal Production), PAV (PAVAGUA), AF (Assut Foundation), LU (La Unió), SEO (SEO-Bird Life, NGO), FC (Fishermen Community), AEA (Acció Ecologista Agró, NGO) and AVA (AVA-ASAJA). On the other hand, the abbreviations of the services are: SS (Supporting services), PS (Provisioning services), RS (Regulation services) and CS (Cultural Services).

As it can be seen from the previous table, cultural services are overrated for all the experts when the AHP method is used. It is noted that some services are adding value to others so there are many interrelationships, all of which are only considered when using ANP. In this case, the cultural services do not add value to the services of the remaining groups whereas the other do add value to them. For instance, the existence of an aesthetic value in the Albufera Natural Park does not give greater value to agriculture, but on the contrary, this activity incorporates aesthetic value to the park at the moment that fields are flooded or are in full production because of it appreciate beauty. Consequently, cultural services have a higher valuation when using AHP because the value that any provisioning, supporting or regulation service is incorporating to a cultural service is entirely considered in the cultural one (the most visible) as the relationships between services are not contemplated with this method. Moreover, AHP can sometimes produce double counts when some criteria are interrelated.

The opposite thing happens with the regulation services since they are undervalued by using AHP because these kinds of services always add value to other services whereas anyone adds value to them, except the supporting ones. For example, the climate regulation helps tourism activities but any provisioning or cultural service can generally influence the climate. This is the opposite situation to the cultural services as part of the value of these services are not counted in AHP because it is distributed in the other ones, all of which are increasing its value due to the regulation ones. 
Regarding to the supporting and provisioning service, the pattern is not as clear as in the other two analyzed groups, although in the provisioning ones, the assessment done by AHP is higher than in ANP in 8 of the 10 experts interviewed. In this case, the relationships between these services in their own groups and between others are bigger and in a double direction: they add value to other services but they also receive value from others.

These differences are important when valuating ecosystem services, therefore it is recommended to use ANP when possible since it is more accurate and it avoids double counting. However, if the objective is the Total Economic Value of any natural area, these differences are hardly ever significant as the overrated services are usually compensated with the undervalued ones.

\section{CONCLUSIONS}

1. The Analytic Multicriteria Valuation Method has traditionally been based on the Analytic Hierarchy Process (AHP) and the Discounted Cash Flow. However, it can also be substituted by the Analytic Network Process (ANP). The first method is faster and easier whereas the second one is more accurate as it considers all the relationships between the different alternatives and criteria, although it involves a higher complexity.

2. Many ecosystem services are adding value to others, as there are many relationships between all of them. However, the cultural services hardly ever add value to the others although, on the opposite direction, those services (regulation, supporting and provisioning services) do add value to the cultural ones. This is why the cultural services are being overvalued when using AHP as this method is not considering these relationships and some value of the other services is being considered only in the cultural ones. The opposite fact happens with the regulation services as they are adding value to the other groups, but anyone adds more importance to it. Therefore, AHP is a method that is underestimating it.

3. The supporting and provisioning services have many relationships in both directions either between them or with the other two groups of ecosystem services so there is not any clear evidence whether AHP is overvaluing or underestimating them. The obtained differences are varying and depending on the expert's opinion.

4. The differences obtained by using each method when valuating ecosystem services cannot easily influence the Total Economic Valuation as the food provisioning service (the reference one when calculating it) is not varying enough between AHP and ANP results. Nevertheless, more research should be done in these terms to ensure it as this was not the main goal of this study.

5. It is recommended to use ANP when valuating ecosystem services since it is more accurate and it considers all the relationships avoiding possible double counting. However, new studies should be done in the future to corroborate it by using more experts and situations.

\section{ACKNOWLEDGMENTS}

We would like to thank the different technicians and the organizations they represent for participating as experts of the interviews and to the public government of the Valencian Community for providing some of the presented data.

\section{REFERENCES}

[1] Baumol, W.J., Oates, W.E. (1998). The Theory of Environmental Policy. 2 Eds. Cambridge, England: Cambridge University Press. http://dx.doi.org/10.1017/CBO9781139173513

[2] Baumol, W.J., Bradford, D.F. (1972). Detrimental externalities and non-convexity of the Production set. Economica, 73(1): 42-54. http://dx.doi.org/10.2307/2552639

[3] Constanza, R., d'Arge, R., de Groot, R., Farber, S., Grasso, M., Hannon, B., Limburg, K., Naeem, S., O’Neill, R.V., Paruelo, J., Raskin, R.G., Sutton, P., Belt, M. (1997). The value of the world's ecosystem services and natural capital. Nature, 387: 253-260.

[4] Cropper, M.L., Oates, W.E. (1992). Environmental economics: A survey. Journal of Economic Literature 30(2): 675-740.

[5] Bellver, J.A., Guitart, V.E. (2012). Valoración de activos ambientales: teoría y casos, 2 Eds. Valencia, Spain: Universitat Politècnica de València.

[6] Farber, S., Constanza, R., Wilson, M. (2002). Economic and ecological concepts for valuing ecosystem services. Ecological Economics, 41: 375-392. http://dx.doi.org/10.1016/S0921-8009(02)00088-5

[7] Soria, J.M. (2006). Past, present and future of La Albufera of Valencia Natural Park. Limnetica, 25(1-2): 135-142.

[8] Hamel, P., Bryant, B.P. (2017). Uncertainty assessment in ecosystem services analyses: Seven challenges and practical response. Ecosystem Services, 24: 1-15. http://dx.doi.org/10.1016/j.ecoser.2016.12.008

[9] Fisher, B., Turner, R.K. (2008). Ecosystem services: Classification for valuation. Biological Conservation, 141(5): http://dx.doi.org/10.1016/j.biocon.2008.02.019

[10] Camacho, V., Ruiz, A. (2012). Marco conceptual y clasificación de los servicios ecosistémicos. Revista Bio Ciencias, 1(4): 1-13.

[11] MEA. (2005). Ecosystems and Human Well-Being: A Framework for Assessment. Washington, DC: Island Press. 49-70.

[12] Saaty, T.L. (1980). The Analytical Hierarchy Process, Planning, Priority. Resource Allocation. RWS Publications, USA.

[13] Saaty, T.L. (2004). Fundamentals of the analytic network process-dependence and feedback in decision-making with a single network. Journal of Systems Science and Systems Engineering, 13(2): 129-157. http://dx.doi.org/10.1007/s11518-006-0158-y 